\title{
Medicinal herbs as possible sources of anti-inflammatory products
}

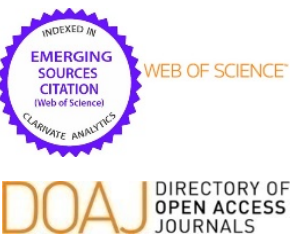

${ }^{1}$ Andreia Corciovă, ${ }^{2}$ Daniela Matei, ${ }^{1}$ Bianca Ivănescu

1. “Grigore T. Popa” University of Medicine and Pharmacy Iasi, ${ }^{1}$ Faculty of Pharmacy, ${ }^{2}$ Faculty of Biomedical Engineering

Corresponding author: Andreia Corciovă,

E-mail address: acorciova@yahoo.com

\begin{abstract}
Plants constitute an inexhaustible source of bioactive compounds that can be valuable for research in the chemistry field of antiinflammatory compounds. This review describes several plants from international and national flora that have been shown to have anti-inflammatory activity in various clinical trials. The paper includes: general aspects regarding the vegetal source, compounds responsible for anti-inflammatory activity, mechanism of action and clinical trials carried out with extracts or products containing standardized extracts.
\end{abstract}

Key words: antiinflamatory activity, Harpagophytum procumbens, Curcuma longa, Zingiber officinale, Boswellia serrata, Symphytum officinale, Rosa canina, Tamus communis, Arnica montana,

\section{Introduction}

The knowledge about plants and their health promoting effects were transmitted by Arabic and Byzantine medicine, being spread to scholars from the Middle Ages and the Renaissance. The knowledge accumulated in the $18^{\text {th }}$ and $19^{\text {th }}$ centuries gradually reaching the scientific foundation of phytotherapy. The founder of true scientific research in phytochemistry and active herbal principles is considered to be the Swedish pharmacist Scheele, who in 1756 extracted crystallized substances (acids: malic, citric, oxalic etc.).

Over the years, research has focused on identifying potentially anti-inflammatory compounds in plants that can be used as complementary remedies or as possible alternative therapeutic agents. Among these we mention: alkaloids, coumarins, flavonoids, monoterpenoids, diterpenoids, triterpenoids, sesquiterpenoids, phenolic compounds, phenylpropanoids, quinones, xanthones etc. [1].

Inflammation is a natural response of the organism, against a variety of aggressions, of non-immunitary origin (chemical, physical, infectious) or immune (autoimmunity, allergies). In the inflammatory process, several mediators are involved: PG (prostaglandins), LT (leukotrienes), lymphokines, cytokines.
Generally, plant compounds act in many ways, inhibiting COX (cyclooxygenase) and LOX (lipoxygenase), but also TNF (tumor necrosis factor) or iNOS (inducible nitric oxide synthase) [2,3].

Hereinafter we will try to present some plants from the international floras that have been evaluated for their anti-inflammatory effects through clinical trials. The plants described are: devil's claw, turmeric, ginger and Indian frankincense tree.

Using plants in therapeutics has expanded a lot over the last decades, with even a "spectacular return to phytotherapy". "Green medicine" and the manufacture of various herbal medicinal products, respectively, little used until now or even unknown, have great potential for many countries, including Romania.

Therefore, we continue to present plants with possible anti-inflammatory action, from the national flora, such as: Symphytum officinale, Rosa canina, Tamus communis, Arnica montana.

\section{Harpagophytum procumbens (devil's claw)}

Harpagophytum procumbens D.C. is native to Southern and Eastern Africa and is largely obtained from Namibia, with lesser amounts from South Africa and Botswana. The name of the genus Harpagophytum means 'grapple plant' in Greek and the specific epithet procumbens means prostrate, referring to the creeping stems of the plant. The 
only other species in the genus is Harpagophytum zeyheri Decne., also found in Southern Africa, but the fruits have much shorter spiny arms than those of $H$. procumbens. It is considered an inferior substitution species, as harpagoside can be completely absent from $H$. zeyheri. Being an important source of income for people living in the Kalahari Desert, devil's claw was over-harvested for medicinal purposes, and it is now in danger of extinction. As a result, both species of Harpagophytum are listed under CITES (Convention on International Trade in Endangered Species) and efforts were initiated to develop micropropagation techniques to solve the problem $[4,5]$.

Devil's claw is a perennial herb with a succulent taproot which belongs to the Pedaliaceae family. The aerial stems are prostrate; they grow up to $2 \mathrm{~m}$ long from a primary tuber whose stout taproot can be $2 \mathrm{~m}$ deep. Secondary storage tubers, resembling elongated sweet potatoes (about $25 \mathrm{~cm}$ long and 6 $\mathrm{cm}$ thick), branch off horizontally. The leaves are large $(6.5 \mathrm{~cm}$ long and $4 \mathrm{~cm}$ wide), simple and opposite, 3-5 lobed. They have a grayish-green color due to the white mucilaginous cells on their surface. The flowers are trumpet shaped, 5-6 cm long, pink, red, or purple (rarely white), with a yellowish center. Fruits are woody, large and flattened (5-15 cm in diameter) only apically dehiscent. They have 4 longitudinal wings with recurved hooks at the margins, or 4 rows of curved arms with recurved spines. This type of fruit gives the plant its common name and help in the dispersal of seeds by getting entangled in the animals' fur. The seeds are dark brown or black. The flowers appear during summer (November to April) and the fruits from January [5].

There are two subspecies of $H$. procumbens: - subsp. procumbens, found in Botswana, Namibia and South Africa, has leaves with five main lobes and fruits with longer spiny arms.

- subsp. transvaalense, found in Zimbabwe and South Africa, has leaves with only three main lobes and fruits with shorter spiny arms [5].

According to the European and British Pharmacopoeia, Harpagophyti radix consists of the cut and dried tuberous secondary roots of Harpagophytum procumbens and/or H. zeyheri. It contains not less than $1.2 \%$ harpagoside calculated with reference to the dried drug [4]. Traditionally, the plant has been used as an analgesic, febrifuge, anti-allergic and as a bitter tonic by bushmen in Africa. The German Commission E approves devil's claw for dyspepsia, appetite stimulation, and degenerative disorders of the musculoskeletal system. Devil's claw has also been used for liver and kidney disorders, as a purgative, an oxytocic, and as a topical agent to treat wounds, ulcers, boils and skin rashes [6].

The main chemical constituents are iridoid glycosides (harpagoside, harpagide, procumbide, 8-para-coumaroyl harpagide), flavonoids (luteolin and kaempferol) [7], aromatic acids (caffeic, cinnamic and chlorogenic acids), phytosterols (beta-sitosterol), sugars (tetrasaccharide, stachyose) and triterpenoids (oleanolic and ursolic acid) [8].

Anti-inflammatory qualities are mainly attributable to iridoid glycosides. The mechanism of action is manifested by: inhibition of NO, inflammatory cytokines (IL-6, IL- $1 \beta$ and TNF- $\alpha$ ) and PGE2, inhibition of arachidonic acid metabolism and eicosanoid biosynthesis, inhibition of COX-2, and suppression NF-kB activation [7, 9]. Clinical studies from the literature on antiinflammatory activity evaluated the effect of various products containing Harpagophytum with harpagoside standardized extracts. Some of the studies are uncontrolled; others compare the results to those obtained with known anti-inflammatory substances.

One of these studies tested tablets containing $60 \mathrm{mg}$ of harpagoside / day standardized extract given to patients with different ages and with nonspecific backpain (first group), knee (group 2) and hip ( group 3) osteoarthritis pain for 8 weeks. In all 3 groups, improvements were observed until week 4 of administration, continuing until the end of the test. In old patients, improvements were fewer than in the case of young people, the best results were observed for group 3 and the weakest for group 2 . Also, group 1 requested an additional amount of NSAIDs compared to the other two groups, but this requirement has decreased over time [10].

Another study compared the administration of tablets containing standardized extract with $57 \mathrm{mg}$ harpagoside for treatment during 4 months in patients with knee and hip osteoarthritis with tablets containing $100 \mathrm{mg} /$ day of diacerhein, compound with recognized properties in 
amelioration of osteoarthritis. The results showed a progressive reduction in symptoms, equivalent to diacerhein. Both groups required NSAIDs or other pain medication. The adverse effects were lower than in the diacerhein group [11].

Devil's claw can be used in doses of 1.8-2.4 mg dried root powder (50-100 mg harpagoside) daily for arthritis and musculoskeletal pain and inflammation or 2-9 g crude aqueous root extract daily for low-back pain and osteoarthritis. No adverse effects are expected if used as recommended, even in long term use, but patients with duodenal ulcers should avoid using devil's claw due to its bitter properties and also pregnant women because of reported oxytocic activity.

Devil's claw extract has been shown to inhibit certain cytochrome P450 enzymes; therefore, may interfere with the metabolisation of numerous pharmaceutical drugs. Because devil's claw lowers blood sugar in animals, caution is advised in association with anti-diabetic drugs. It also reduces arterial blood pressure and heart rate in animals, has antiarrhythmic and some anticoagulant activity, so precaution should be taken when administered in conjunction with similar effect medications and dosages may need to be adjusted [6].

\section{Curcuma longa (turmeric)}

Curcuma longa L. is an upright, perennial herb, about $1 \mathrm{~m}$ tall and a member of the ginger family (Zingiberaceae). The rhizome is thick and wears the ring marks from the bases of old leaves. Rhizomes many branched, fleshy, cylindric, orange or bright yellow, aromatic, often with tuber-bearing roots. The leaves are large, oblong lanceolate or elliptic, up to $90 \mathrm{~cm}$ long, glabrous, with attenuate base and shortly acuminate apex. Each leafy shoot (pseudostem) bears 8-12 leaves. Flowers are infertile and unable to generate viable seeds. They are pale yellow, grouped in cylindric spikes, 10-15 $\mathrm{cm}$ long, terminal on pseudostems, covered by the leaf sheath. The fertile bracts are pale green, ovate or oblong; coma bracts are spreading, white and green, sometimes tinged reddish purple. The seeds are small, ovoid, brown and non-viable.

Turmeric is sterile, but it does grow vigorously from the rhizomes. Its exact origin is unknown, but is believed to have originated by selection and propagation of a hybrid between wild turmeric (Curcuma aromatica) and other Curcuma species.
Turmeric is not found in the wild and is only known as a domesticated plant. India is the world's greatest producer $(93,7 \%$ of the total world production), consumer and exporter of turmeric. Turmeric is cultivated extensively throughout the tropics, in Bangladesh, China, Thailand, Cambodia, Malaysia, Indonesia and the Philippines [12].

Its rhizomes are the source of a culinary ingredient and a bright yellow dye. The primary and secondary rhizomes are dug up, steamed or boiled, and dried. Turmeric is an essential component of Indian curry. It was known, in medieval Europe, as Indian saffron because it was used as a substitute for the extremely pricey condiment. The spice turmeric is a yellow-brown powder with a characteristic musky, earthy aroma and a pungent, slightly bitter flavor.

Turmeric was known in India for at least 2,500 years, where has been used for a long time in traditional medicine, mainly in Ayurvedic and Unani systems. Curcuma longa is a well studied medicinal plant, with numerous pharmacological activities: antioxidant, anti-inflammatory, anticarcinogenic, hepatoprotective, neuroprotective, cardioprotective and antiischemic, thrombosuppressive, vasodilator, antispasmodic and bronchodilator, antidepressant, hypoglycemic and anti-arthritic [4].

Among the chemical constituents of Curcuma longa, we mention curcuminoids (curcumin, monodemethoxycurcumin

and bisdemethoxycurcumin), volatile oils (turmerone, atlantone, zingberone), sugars, proteins and resins. The active constituent, curcumin, was identified in 1910 by Lampe and Milobedzk.

The anti-inflammatory effect of curcumin is most likely due to the ability to inhibit COX-2, LOX and iNOS enzymes. It inhibits the production of inflammatory cytokines such as TNF- $\alpha$, interleukin (IL) $-1,-2,-6,-8$, and -12, monocyte chemoattractant protein-1 (MCP1), migration inhibitory protein, and down-regulates mitogenactivated protein and Janus kinases [13, 14].

From the literature data demonstrating the clinical efficacy of curcumin, there are two studies (3 and 8 months respectively) that used a curcuminphosphatidylcholine-type complex. A decrease in joint pain and a joint improvement associated with excellent tolerability was observed, suggesting that 
this complex is worth to consider for long-term complementary administration in osteoarthritis [15, 16].

Among the comparative studies we mention: the use of curcumin at a dose of $1200 \mathrm{mg} /$ day compared with phenylbutyazone $300 \mathrm{mg} /$ day in patients with rheumatoid arthritis, 20 to 55 years old. It has been observed that after curcumin administration clinical manifestations such as joint swelling and stiffness in the morning improved and no adverse reactions were observed [17].

Another study compared curcumin at a dose of 500 $\mathrm{mg}$ / day and diclofenac sodium $50 \mathrm{mg}$ / day, alone or in combination, in patients with rheumatoid arthritis. The group that received curcumin showed the highest percentage of improvement and no adverse reactions. No synergistic or additive effect was observed in combination with diclofenac, which encourages administration of curcumin alone [18].

\section{Zingiber officinale (ginger)}

Zingiber officinale Roscoe (Zingiberaceae family) is an herbaceous perennial which grows pseudostems about a meter tall. Rhizomes are branched, yellowish inside, thickened, fleshy and strongly aromatic. Leaves are sessile, lanceolate or linear-lanceolate, glabrescent with membranous ligule slightly 2-lobed. Inflorescences arising from rhizomes are cone-shaped spikes, with pale green bracts, sometimes yellowish at margin, ovate, with mucronate apex. Protruding just beyond the outer edge of the bracts, the flowers are pale yellow in colour with a purplish lip that has yellowish dots and striations. Flowering stems are seldom produced in cultivated plants, usually in October [19].

Its generic name Zingiber is derived from the Greek "zingiberis", which comes from the Sanskrit name of the spice, "singabera", meaning "shaped like a horn" or "horn root," based on its appearance. The specific epithet officinalis means "of the dispensary" in Latin, alluding to the medicinal properties of the plant. Indians and Chinese are believed to have produced ginger as a tonic root for over 5000 years to treat many ailments. It first appeared in the writings of Confucius in the 5th century BC and it has been used medicinally in the West for at least 2000 years.
Zingiber officinale is possibly native to India where has been cultivated from the earliest times. The plant is unknown in the wild state. The tropical herbaceous plant is the source of a well known spice produced from its rhizome (underground stem), ginger. The spice was used by the Greek and Romans, and was a common article of European commerce in the Middle Ages.

According to British Pharmacopoeia, Zingiberis rhizoma is the scraped or unscraped rhizome of Zingiber officinale. The plant which yields the official ginger is grown in many tropical regions, such as India (Cochin, Calicut and Bengal), Africa (Nigeria, Sierra Leone), China, the East Indies, Cochin China, Australia and Florida [4].

The composition of ginger includes: essential oil (gingerol, zingberene, $\beta$-phellandrene, $\beta$ bisabolene, camphene, $\alpha$ - farnesene, zingiberol, felandrene, borneol, cineol, citral and borneol), phenols, starch, mucilages, resins, potassium, zinc, calcium, copper, magnesium, vitamins B6, C and D. Ginger contains about $1-2 \%$ of volatile oil to which the drug owes its specific aroma. The pungency of ginger is due to gingerol, an oily liquid consisting of homologous phenols [4].

Anti-inflammatory action is due to: inhibition of cyclooxygenase, especially COX-2, inhibition of leukotriene synthesis by lipoxygenase inhibiting action, blocking the production of interleukins (IL1 , IL-12) and TNF- $\alpha$. Ginger is also thought to work at central level, potentially through interaction with the vanilloid receptor, which is known to play a role in the processing of nociceptive signals [20].

Administration of ginger powder had an ameliorative effect in patients with rheumatoid arthritis, osteoarthritis and muscle discomfort. In a study of 56 patients with rheumatoid arthritis, osteoarthritis and with muscular discomfort, among arthritis patients, more than three-quarters showed improvement in pain and swelling to varying degrees. All patients with muscle discomfort felt relief of pain. None of the patients reported adverse effects during treatment [21].

Also, ginger extract was compared with ibuprofen, diclofenac and indomethacin in osteoarthritis patients. Ginger is as effective as these compounds, but with negligible side effects. Therefore, in patients with NSAIDs intolerance, ginger can be used as a substitution product [22-24]. 


\section{Boswellia serrata (Indian frankincense tree, olibanum tree)}

Boswellia serrata Roxb. is a tree belonging to Burseraceae family that grows in dry mountainous regions of India, Northern Africa and the Middle East. The genus Boswellia comprises about 25 species, many of which yield important resins, such as $B$. sacra, $B$. carterii and $B$. frereana, 'true Frankincense' producing trees. The generic name Boswellia is given after Dr. James Boswell of Edinburgh Botanical Garden and friend of William Roxburgh, Director of Indian Botanical Garden, Calcutta. The specific name, serrata, comes from serra (a saw) referring to the toothed leaf margins. Boswellia serrata is a moderate-sized to large (9$15 \mathrm{~m}$ height), deciduous tree with a light, spreading crown and somewhat drooping branches. Bark is very thin, greyish-green, peeling off in thin, papery flakes. Leaves are alternate, imparipinnate, 20-45 $\mathrm{cm}$ in length; leaflets 13-25, opposite, sessile, lanceolate or ovate-lanceolate, crenate, very variable in size. Flowers are white, grouped in long pubescent racemes $(10-20 \mathrm{~cm})$, shorter than the leaves, at the ends of branches, but not terminal. The fruits are triangular 3-celled drupes with winged seeds. Flowers appear from the end of January to March-April and drupes ripen in MayJune [25].

Boswellia serrata is the source of a gum-resin called 'salai guggul' or 'Indian olibanum' obtained from the bark after injury. The gum resin is fragrant and burns with a pleasant odour and is used as incense in religious ceremonies. Boswellia serrata is one of the ancient and most valued herbs in Ayurveda which describes the antirheumatic (antiarthritis) activity of the gum-resins of trees, and also its use as an effective remedy for diarrhoea, dysentery, ringworm, boils, fevers (antipyretic), skin and blood diseases, cardiovascular diseases, mouth sores, bad throat, bronchitis, asthma, cough, vaginal discharges, hairloss, jaundice, hemorrhoids, syphilitic diseases, irregular menses and stimulation of liver. Modern research support its use as an antiarthritic, antiinflammatory, antihyperlipidemic, antiatherosclerotic, analgesic and hepatoprotective agent [26].

The composition of Boswellia serrata contains: pentacyclic triterpenic acids - boswellic acids ( $\beta$ - boswellic acid, acetyl $\beta$-boswellic acid, 11-keto- $\beta$ boswellic acid), tetracyclic triterpenic acids (tirucal 8,24-dien-21-oic acids), monoterpenes ( $\alpha$-tujene), diterpene (incensol, incensol oxide, iso-incense oxide, seratol), triterpenes ( $\alpha$-, $\beta$-amirin) [26].

The anti-inflammatory effect is triggered by the binding of boswellic acids to the LOX enzyme and the inhibition of 5-LO pro-inflammatory enzyme synthesis, including 5-hydroxyeicosatetraenoic acid (5-HETE) and leukotriene B4 (LTB-4). Other anti-inflammatory constituents of the plant, such as quercetine, also block this enzyme but in a general way, as an antioxidant, while boswellic acids appear to be 5-LO-specific inhibitors. 3-acetyl-11keto-p-boswellic acid is the most potent inhibitor of 5-LO [27, 28].

The efficacy of Boswellia serrata extract in patients with osteoarthritis was demonstrated in a randomized, double-blind, placebo-controlled study on 30 patients with knee osteoarthritis. When a Boswellia serrata product was administered, a dramatic reduction in the frequency of joint and pain swelling and an increase in joint flexibility and walking distance at the end of the treatment period were observed [29].

Unlike NSAIDs, which are well known to disrupt glycosaminoglycan synthesis, thus accelerating joint damage under arthritic conditions, boswellic acids have been shown to significantly reduce glycosaminoglycan degradation. An in vivo study that examined the effect of Boswellia and ketoprofen on glycosaminoglycan metabolism showed that Boswellia significantly reduced glycosaminoglycan degradation compared to controls, whereas ketoprofen determined a reduction in total glycosaminoglycan content in the tissues [30].

\section{Symphytum officinale (comfrey)}

Symphytum officinale L. or common comfrey belongs to Boraginaceae family. It is an herbaceous perennial, encountered at the edge of standing waters, brooks, through wet meadows and swampy places. The underground part is a short and thick rhizome, from which start fleshy, fusiform roots up to $30 \mathrm{~cm}$ long. The whole underground part has a black glossy color on the outside, with longitudinal ribs, and white or white-yellow color on the inside. The stem is erect, $20-100 \mathrm{~cm}$ high, branched, edged or winged, coarsely hairy, with setiform bristles, 
slightly bent upwards. The leaves are alternate, hairy, elliptic or oval-lanceolate, decurrent, with winged petiole. The size of the leaves decreases from the base to the top of the stem. The flowers are tubular, pink to purple, seldom white, grouped in scorpioid cymes at the top of the branches. They are bisexual, tetracyclic and pentamerous, with radial symmetry and appear in mid-spring to early summer. The fruits are nutlets grouped by 4 and housed by the persistent calyx [31].

Native in Europe, the plant was also naturalized in Northern America, where it rapidly spread. Symphytum officinale has been used in the traditional Balkan medicine internally or externally for treatment of disorders of the locomotor system and gastrointestinal tract, rheumatism and gout. Genus name Symphytum comes from the Greek words symphyo meaning to grow together and phyton for plant as the plant was believed to help heal wounds. Specific epithet officinale means sold in shops and was often applied to plants with supposed medicinal properties [32].

The roots (Symphyti radix) and aerial parts (Symphyti herba) of comfrey have long been important drugs in herbal medicine for the treatment of pulmonary and gastric conditions and various rheumatic complaints. The discovery of hepatotoxic pyrrolizidine alkaloids in S. officinale and S. uplandicum (Russian comfrey) has cast doubt on the desirability of using the drug for internal medication [33]. The United States Food and Drug Administration issued a ban of comfrey products marketed for internal use, and a warning label for those intended for external use. Anyway, there are fully licensed medicinal products available today containing depleted or alkaloidsfree processed extracts. Still, some authors recommend a restriction of the duration of treatment, even with topical preparations. In Germany, the restriction limiting application to 46 weeks/year applies only to preparations containing more than $10 \mu \mathrm{g}$, but less than $100 \mu \mathrm{g}$ pyrrolizidine alkaloids (daily allowance) [32].

Comfrey contains many volatile oils, mucilages, alkaloids (simfitocinoglossine, consollicine, consolidin, coniferidin, cinoglosin, unsaturated necins), allantoin, choline, asparagine, catechic tannins, phenolcarboxylic compounds (caffeic acid, chlorogenic acid) triterpenes, aminoacids and carotenoids.
Allantoin stimulates the regeneration of connective tissue, bone and cartilage [34].

Regarding the mechanism of anti-inflammatory action, it has been found that a glycopeptide isolated from the Symphytum officinale aqueous extract inhibits the release of prostaglandins and leukotrienes by decreasing expression of phospholipase $\mathrm{A}_{2}$ [35].

It is clinical proved that comfrey relieves pain, inflammation and swellig of muscles and joints in the case of degenerative arthritis, acute back pain, sprains, bruises and strains after injuries and sports injuries, also in children over 3 years old [32].

In a survey conducted among the members of the Association of Master Herbalists, the College of Practitioners of Phytotherapy and the National Institute of Medical Herbalists from England, it has been shown that comfrey is commonly recommended as a cream for tendons, ligaments, muscle problems and fractures [36].

Another study tested comparatively two topical creams that contained, in addition to 10 and $20 \%$ comfrey, tannic acid and eucalypt with a reference cream that contains only eucalypt. Creams were applied 3 times a day for 6 weeks. Both topical active formulations with comfrey were effective in relieving pain and stiffness and improving physical functioning. Also, the results were superior to the reference eucalypt cream. Side effects were rash and itching that has been resolved quickly by changing applications [37].

Furthermore, an ointment with comfrey was compared with diclofenac gel in the treatment of acute sprains of the unilateral ankle (4 applications / day for 7 days). The pain response to the pressure on the injured area, the swollen joint circumference, the individual spontaneous pain in resting, the frequency of using the rescue medication (an anti-inflammatory) as well as the general efficacy and tolerability were measured. It has been shown that the comfrey gel is slightly superior to the diclofenac gel [38].

\section{Rosa canina (dog rose, rose hips)}

Rosa canina L., family Rosaceae, is a wild rose species native to Europe, northwest Africa, and western Asia. The botanical name is derived from the common names 'dog rose' in several European languages, including classical Latin and ancient Greek. The name arose out of the belief in classical 
times that the root was a cure for the bite of a mad dog.

Dog rose is deciduous shrub, 2-3 m high, with long arched branches having strong thorns. Leaves are alternate, imparipinnately-compound with 5-7 oval folioles with toothed edge. At the base the leaves are provided with 2 stipules connate with the petiole. The flowers are large, solitary or grouped by $2-3$, hermaphrodites, pentamerous, with radial symmetry. They are generally light pink, but can vary between a deep pink and white, and appear between May and June. The fruits are false berries called rosehips, oval, bright red and glossy when mature, $1.5-2 \mathrm{~cm}$ long. The upper end bears the scars of the five fallen sepals. False berry is a pulpy, juicy indehiscent accessory fruit with many seeds. It is formed from an inferior ovary, in which the floral tube (hypanthium) including the basal parts of the sepals, petals, and stamens ripen along with the ovary. The achenes (true fruits) are hairy and inserted on the inner face of the urceolate hypanthium [31].

Rose hips consist of the incompletely dried, almost ripe fruits, with the achenes removed, of various species of Rosa including Rosa canina, Rosa villosa and Rosa pendulina. The hips should be collected between the period when they just begin to change colour and when they are fully red, and used for the preparation of galenicals as soon as possible. Rose hips are usually used for their vitamin content and the European Pharmacopoeia requires a minimum $0.3 \%$ ascorbic acid for the official drug [33].

Among the classes of compounds contained in the dog rose, we mention: vitamins $\left(\mathrm{C}, \mathrm{A}, \mathrm{B}_{1}, \mathrm{~B}_{2}\right.$, and $\mathrm{PP})$, phenolic acids, proanthocyanidins, tannins, flavonoids, unsaturated and polyunsaturated fatty acids, phospholipids, minerals, galactolipids, and carotenoids [39].

It has been shown that active principles of Rosa canina have anti-inflammatory action and antioxidant properties. In particular, a galactolipid which has been shown to inhibit neutrophil chemotaxis in peripheral blood was isolated [40].

Jäger et al. have shown that linoleic and $\alpha$-linolenic acids inhibit COX-1 and COX-2 in vitro [41, 42]. In addition, triterpenic acids exhibit COX and lipoxygenase inhibitory properties [43].

Willich et al. investigated the administration of standardized powder to patients with rheumatoid arthritis in the form of $5 \mathrm{~g} /$ day capsules for 6 months. It has been observed that the symptoms have improved [44].

Another clinical trial used rose and seed powder at a dose of $3 \mathrm{mg}$ galactolipid / day for 54 weeks to treat chronic back pain, unspecified back pain, unspecified knee and hip osteoarthritic pain and specific pain. An improvement was observed, regardless of the group. The degree and timing of improvement were equivalent to those seen in similar surveillance of patients receiving an aqueous Harpagophytum extract. Changes were more pronounced in case of patients with higher degrees of pain and disability, but were generally unrelated to patient characteristics. No adverse effects were noted [45].

Another evidence of the anti-inflammatory action of galactolipid was demonstrated in a paper in which three randomized controlled trials involving 287 arthritic patients with a median treatment period of 3 months were performed. The antiinflammatory power of dog rose in arthritis is similar to that of non-steroidal anti-inflammatory drugs, although its mode of action is different. Unlike these drugs, the dog rose has no gastrointestinal or cardiovascular side effects [46].

\section{Tamus communis / Dioscorea communis (black briony)}

Tammus communis L. or Dioscorea communis Caddick \& Wilkin, belongs to Dioscoreaceae family, which comprises over 600 species, mostly tropical and sub-tropical plants. The genus and family are named after the ancient Greek physician and botanist Dioscorides. Tubers of many Dioscorea species (yams) have long been used for food, as they are rich in starch. Many of these are toxic when fresh, but can be detoxified and eaten. The toxins found in many species of yam are steroidal saponins, which can be used as starting material for the synthesis of steroid hormones for use in medicine and as contraceptives. Diosgenin is the principal sapogenin from Dioscorea plants used by industry. Tammus communis is highly poisonous and should not be ingested at all, at least when raw. Therefore, it is not used internally; however, it has been used as a poultice for bruises and inflamed joints. Researchers have identified calcium oxalate deposits and histamines in the plant, which may contribute to skin irritation and contact dermatitis associated with black bryony [33]. 
Dioscorea communis is a native spontaneous species widespread throughout southern and central Europe, northwest Africa and western Asia. It is a herbaceous, perennial plant with a climbing stem 2$4 \mathrm{~m}$ high, that twine clockwise. The root is elongated fleshy, cylindrical, tuberiform, sometimes branched. The leaves are alternate, petiolated, and vivid-green, deeply ovate-cordate, with entire margins, acuminate. The plant has separate male and female individuals. Male flowers, grouped in elongated racemes, are urceolate, tubular, and greenish-yellow. Female inflorescence is a shorter raceme with few flowers. The fruit is a red, globose berry, with reddishbrown globular seeds. The plant grows in shady forests, shrubberies, hedges, and forests edges [31]. Black bryony contains: steroidal saponosides, alkaloids, tannins, calcium oxalate. The use of the plant after the fresh harvesting of the parts of plants (leaves, flowers and mainly fruits) or application as water / alcohol macerates is supported by local antiinflammatory effects on minor lesions and by relieving inflammations affecting the joints, muscles and other subcutaneous tissues [47, 48].

Hydrogels are effective formulations to incorporate plant extracts, providing good percutaneous absorption, non-greasy texture and easy application. Thus, tests have been made for local anti-inflammatory effects in relieving inflammations affecting the joints, muscles and other subcutaneous tissues in combination with Bryonia dioica and Lonicera periclymenum fruits in hydrogels [47, 48].

\section{Arnica montana (arnica)}

Arnica montana L. (Asteraceae family) is a perennial herbaceous plant with a thick, cylindrical, $10 \mathrm{~cm}$ long rhizome. The rhizome is horizontally or obliquely arranged in the ground and has numerous fibrous roots. The plant has a basal rosette of 5-7 (10) elliptic or oval elliptic leaves. The cylindrical stem is simple, solitary, 20-60 cm high with one or two pairs of small, opposite leaves. The base of the stem is often reddish and glandular. The basal leaves may be glabrous or rough due to short hairs. The lateral veins of the leaves are almost parallel to the main one. The inflorescence is a large flowerhead, 4-8 cm in diameter. The head has 12-20 yellow ray flowers, two times as long as the involucre, and many orange tubular disk flowers.
The involucre is made of two rows of triangularlanceolate folioles, glandular, often reddish and acute. The receptacle is pubescent, and the fruits are $5 \mathrm{~mm}$ long cylindrical achenes, attenuated at both extremities, hairy, with a coarse black pappus $8 \mathrm{~mm}$ long. Arnica montana blooms in June-August; the flowers appear only in the second year of vegetation [31].

The genus name is derived from the Greek word ptarmike, which means to sneeze, because the plants cause sneezing, and the specific epithet refers to mountains, where the plants grow. The species is considered to be of European origin, has a broad ecological spectrum, it is characteristic for wet meadows and wetlands in the mountainous and subalpine area (from $600 \mathrm{~m}$ to $2800 \mathrm{~m}$ altitude). It has been introduced into culture as a medicinal herb because of its therapeutic properties, but also as an element in floral landscaping. In Romania, it is found across the Carpathian Mountains, especially in Transylvania and in northern Moldova, where it is declared a protected species. Due to habitat fragmentation, agricultural intensification, and medicinal collection (about 50 tones / year in Europe), a rapid decline of this plant in Europe has occurred. Arnica montana is a plant under strict protection in many countries and included in the IUCN Red list of threatened species [49].

The medicinal plant product consists of whole or partially broken dried flower-heads of Arnica montana, shortly called Arnicae flos, which are official in European and British Pharmacopoeia. Harvesting is a key step for this species. Within 48 hours of blooming, arnica must be harvested, stored and delivered to the processing units. Obtaining quality material requires the inflorescence to be harvested only in sunny weather conditions after the dew has passed.

After many pharmacological experiments carried out in recent decades, Arnica montana has shown primarily the anti-inflammatory action on various inflammation models. This is the main action and the most important one mentioned in the literature [50, 51].

Among the compounds present in the Arnica montana, the sesquiterpene lactones, helenaline type, helenaline esters and 11,13-dihydrohelenaline esters with acetic, isobutyric, isovalerianic and tiglic acids, are responsible for the antiinflammatory action, reflected also by the 
European Pharmacopoeia which stipulates that arnica flowers must have a minimum content of 0.4 $\%$ expressed as helenalinetiglinat [51, 52, 53].

Extracts as well as internal preparations of Arnica monatana are toxic and therefore some authors recommend arnica only in external administration [54].

Studies have been conducted on the use of topical Arnica preparations to improve symptoms in osteoarthritis. Tfhe effects of gels with ibuprofen (5 $\%$ ) and arnica (50 g tincture / 100 g, 1:20) were compared in patients with symptomatic active osteoarthritis. Pain relief and hand function were investigated after 21 days of treatment. There were no differences between the two groups in relieving pain and hand functions. It results that the arnica gel is an alternative to ibuprofen treatment in the case of pain and handiness of hand movement in the case of osteoarthritis [55].

In homeopathy, Arnica montana holds a leading role in the anti-inflammatory and analgesic treatment of mild traumatic lesions as well as in the field of suppressing pre- and postoperative effects. Specialists demonstrated its efficacy through clinical trials, when it was observed a lack of side effects, lack of interaction with other drugs and safety in administration.

In a study used for clarifying the efficacy of homeopathic remedies based on Arnica montana regarding the wound healing after orthopedic surgery, a comparision with diclofenac was performed. The efficacy of Arnica D4 10 pills (orally administrated, 3 times daily) and sodium diclofenac, $50 \mathrm{mg}$ (orally administrated, 3 times daily), was investigated 4 days after surgery. A first observation was that Arnica D4 does not suppress hemoperfusion as in the case of diclofenac and thus contributes to a faster healing of the lesions. Also, improved mobility was observed after 4 days postoperatively, this being an additional important clinical parameter, which was better for arnica D4 than Diclofenac. Thus, the authors of the study believe that Arnica D4 can be used instead of diclofenac. At the same time, there was a better tolerance for Arnica D4 than Diclofenac, and no gastroprotective therapy was needed. There is also a decrease in the cost of medication by about $60 \%$ compared to the use of Diclofenac [56].

\section{Conclusions}

The use of plant compounds may be of greater safety compared to synthetic drugs, current research being directed not to use the entire plant, but to isolate, characterize, test and further use in pharmaceuticals only the compounds that have been proven through preclinical and clinical tests to have the desired therapeutic effect.

The secret of plant life, the intimacy of biochemical processes carried out at the cellular and molecular levels in the context of the body as a whole, have been largely resolved, but there are still unknown facts, which can be elucidated by a constant, persevering and exigent concern.

\section{References}

1. Perez R.M. Anti-inflammatory activity of compounds isolated from plants. The Scientific World.2001; 1: 713-784.

2. Vashishtha V., Sharma Ganesh N., Gaur M., et al. A review on some plants having anti-inflammatory activity. The Journal of Phytopharmacology. 2014; 3(3): 214-221.

3. Cristea A. Tratat de farmacologie. Bucureşti: Editura, 2006.

4. Evans W.C. Trease and Evans Pharmacognosy $16^{\text {th }}$ Edition, W.B. Saunders Edinburgh, 2009.

5. Devil's claw Production Guideline. Department of Agriculture, Forestry and Fisherie. Republic of South Africa, Pretoria, 2015.

6. Bone K., Mills S. Principles and Practice of Phytotherapy. Churchill Livingstone, Edinburgh, 2013.

7. McGregor G., Fiebich B., Wartenberg A., et al. Devil's Claw (Harpagophytum procumbens): An anti-inflammatory herb with therapeutic potential. Phytochemistry Reviews.2005; 4: 47-53.

8. Bradley P.R., British Herbal Compendium Vol. 1. Dorset, UK: British Herbal Medicine Association; 1992.

9. Huang T.H.-W., Tran V.H., Duke R.K., et al. Harpagoside suppresses lipopolysaccharideinduced iNOS and COX-2 expression through inhibition of NF- $\kappa \mathrm{B}$ activation. Journal of Ethnopharmacology. 2006; 104(1-2):149-155.

10. Chrubasik S., Thanner J., Künzel O., et al. Comparison of outcome measures during treatment with the proprietary Harpagophytum extract doloteffin in patients with pain in the lower back, knee or hip. Phytomedicine. 2002; 9(3):181-194.

11. Chantre P., Cappelaere A., Leblan D., et al. Efficacy and tolerance of Harpagophytum 
procumbens versus diacerhein in treatment of osteoarthritis. Phytomedicine. 2000; 7: 177-183.

12. Velayudhan KC, Dikshit N, Abdul Nizar M. Ethnobotany of turmeric (Curcuma longa L.) Indian J Tradit Know. 2012; 11: 607-614.

13. Menon V.P., Sudheer A.R. Antioxidant and antiinflammatory properties of curcumin. Advances in experimental medicine and biology. 2007; 595: 105-125.

14. Zhou H., Beevers C.S., Huang S. Targets of curcumin. Curr Drug Targets. 2011; 12(3): 332347.

15. Belcaro G., Cesarone M.R., Dugall M., et al. Product-evaluation registry of Meriva (R), a curcumin-phosphatidylcholine complex, for the complementary management of osteoarthritis. Panminerva Med. 2010; 52(2 Suppl 1): 55-62.

16. Belcaro G., Cesarone M.R., Dugall M., et al. Efficacy and safety of Meriva (R), a curcuminphosphatidylcholine complex, during extended administration in osteoarthritis patients. Altern Med Rev. 2010; 15(4):337-344.

17. Deodhar S.D., Sethi R., Srimal R.C. Preliminary study on antirheumatic activity of curcumin (diferuloylmethane). Indian J Med Res 1980; 71: 632-634.

18. Chandran B., Goel A. A randomized, pilot study to assess the efficacy and safety of curcumin in patients with active rheumatoid arthritis. Phytother Res. 2012; 26(11):1719-1725.

19. Dhanik J, Arya N, Nand V. A Review on Zingiber officinale. Journal Pharmacogn. Phytochem. 2017; 6(3): 174-184.

20. Black C.D., Herring M.P., Hurley D.J., et al. Ginger (Zingiberofficinale) reduces muscle pain caused by eccentric exercise. The Journal of Pain. 2010; 11(9): 894-903.

21. Srivastava K. C., Mustafa T. Ginger (Zingiberofficinale) in rheumatism and musculoskeletal disorders. Medical Hypotheses. 1992; 39(4):342-348.

22. Drozdov V.N., Kim V.A., Tkachenko E.V., et al. Influence of a specific ginger combination on gastropathy conditions in patients with osteoarthritis of the knee or hip. The Journal of Alternative and Complementary Medicine. 2012; 18(6):583-588.

23. Khalvat A. Comparing the effects of ginger (Zingiberofficinale) extract and ibuprofen on patients with osteoarthritis. Archives of Iranian Medicine. 2005; 8(4): 267-271.

24. Haghighi A., Tavalaei N., Owlia M. B. Effects of ginger on primary knee osteoarthritis. Indian Journal of Rheumatology. 2006; 1(1):3-7.
25. Orwa C., Mutua A., Kindt R., Jamnadass R., Anthony S. 2009 Agroforestree Database:a tree reference and selection guide version 4.0 (http://www.worldagroforestry.org/sites/treedbs/tr eedatabases.asp)

26. Siddiqui M. Z. Boswellia serrata, a potential antiinflammatory agent: an overview. Indian J. Pharm. Sci. 2011; 73(3): 255-261.

27. Ammon H.P. Boswellic acids (components of frankincense) as the active principle in treatment of chronic inflammatory diseases. Wien Med Wochenschr. 2002; 152: 337-378.

28. Ammon H.P. Boswellic acids in chronic inflammatory diseases. Planta Med. 2006; 72: 1100-1116.

29. Kimmatkar N., Thawani V., Hingorani L., et al. Efficacy and tolerability of Boswelliaserrataextract in treatment of osteoarthritis of knee - a randomized double blind placebo controlled trial. Phytomedicine. 2003; 10(1):3-7.

30. Reddy G.K., Chandraksan G., Dhar S.C. Studies on the metabolism of glycosaminoglycans under the influence of new herbal ant-inflammatory agents. Biochem Pharm. 1989; 38: 3527-3534.

\section{References 2}

31. Flora RPR-RSR; Editura Academiei Române, Bucureşti, 1952-1970.

32. Staiger C. Comfrey root: from tradition to modern clinical trials. Wien Med Wochenschr. 2013; 163: 58-64.

33. Evans W.C. Trease and Evans Pharmacognosy $16^{\text {th }}$ Edition, W.B. Saunders Edinburgh, 2009.

34. Mills S. The dictionary of modern herbalism. Wellingborough: Thorsons Publishers Ltd; 1985.

35. Vogl S., Picker P., Mihaly-Bison J., et al. Ethnopharmacological in vitro studies on Austria's folk medicine - an unexplored lore in vitro antiinflammatory activities of 71 Austrian traditional herbal drugs. J. Ethnopharmacol. 2013; 149: 750771.

36. Frost R., O'Meara S., MacPherson H. The external use of comfrey: a practitioner survey. Complement. TherClin. Pract.2014; 20: 347-355.

37. Smith D.B., Jacobson B.H. Effect of a blend of comfrey root extract (Symphytum officinaleL.) and tannic acid creams in the treatment of osteoarthritis of the knee: randomized, placebo-controlled, double-blind, multiclinical trials. J.Chiropr. Med.2011; 10:147-156.

38. Predel H.G., Giannetti B., Koll R., et al. Efficacy of a comfrey root extract ointment in comparison to a diclofenac gel in the treatment of ankle distortions: results of an. observer-blind, 
randomized, multicenter study. Phytomedicine. 2005; 12: 707-714.

39. Chrubasik, C., Roufogalis, B.D., Müller-Ladner, U., et al. A systematic review on the Rosa canina effect and efficacy profiles. Phytother. Res. 2008; 22: 725-733.

40. Larsen E., Kharazmi A., Christensen L.P., et al. An anti-inflammatory galactolipid from Rose hip (Rosa canina) that inhibits chemotaxis of human peripheral blood neutrophils in vitro. J. Nat. Prod. 2003; 66: 994-995.

41. Jäger A.K., Eldeen I.M.S., van Staden J. et al. COX-1 and COX-2 activity of rose hip.Phytother. Res. 2007; 21: 1251-1252.

42. Jäger A.K., Petersen K.N., Thomasen G., et al. Isolation of linoleic and alpha-linolenic acids as COX-1 and -2 inhibitors in rose hip. Phytother. Res. 2008; 22: 982-984.

43. Wenzig E.M., Widowitz U., Kunert O., et al. Phytochemical composition and in vitro pharmacological activity of two rose hip (Rosa canina L.) preparations. Phytomedicine. 2008; 15: 826-835.

44. Willich S.N., Rossnagel K., Roll S., et al. Rose hip herbal remedy in patients with rheumatoid arthritis - a randomized controlled trial. Phytomedicine. 2010; 7: 87-93.

45. Chrubasik C., Wiesner L., Black A., et al. A oneyear survey on the use of a powder from Rosa caninalito in acute exacerbations of chronic pain. Phytother. Res. 2008; 22: 1141-1148

46. Cohen M. An evidence based herbal medicine for inflammation and arthritis. Aust. Fam. Physician. 2012; 41(7): 495-498

47. Rafael M., Barros L., Carvalho A.M., et al. Topical anti-inflammatory plant species: bioactivity of Bryonia dioica, Tamus communis and Lonicera periclymenum fruits. Ind. Crops Prod. 2011; 34: 1447- 1454.

48. Barreira J.C.M., Pereira E., Duenas M., et al. Bryonia dioica, Tamus communis and Lonicera periclymenum fruits: characterization in phenolic compounds and incorporation of their extracts in hydrogel formulations for topical application. Ind. Crops Prod. 2013; 49: 169- 176.

49. Bisset N.G., Wichtl M.Herbal Drugs and Phytopharmaceuticals.Boca Raton, London, New York, Washington: CRC Press. 2001.

50. Pljevljakusic D., Jankovic T., Jeacic S. el al, Morphological and chemical characterization of Arnica montana L., under different cultivation models, Ind. Crops Prod. 2014; 52: 233-244.

51. Sugier D., Kolodziej B., Bielinska E., The effect of leonardite application on Arnica montana L. yielding and chosen chemical properties and enzymatic activity of the soil, J. Geochem. Explot.2013; 129: 76-81.

52. Pljevljakusic D., Rancic D., Ristic M. el al., Rhizome and root yeld of the cultivated Arnica montana L., chemical composition and histochemical localization of essential oil.Ind. Crops Prod. 2012; 39: 177-189.

53. Staneva J., Denkova P. el al-Quantitative analysis of sesquiterpene lactones in extract of Arnica montana L. by ${ }^{1}$ HNMR spectroscopy, J. Pharm. Biomed. Analysis.2011; 54: 94-99.

54. Temelie M.Enciclopedia plantelor medicinale spontane din Romania, Bacau:Rovimed. 2006.

55. Widrig R, Suter A, Saller R, et al. Choosing between NSAID and arnica for topical treatment of hand osteoarthritis in a randomised, double-blind study, Rheumatol Int. 2007; 27(6): 589-591.

56. Karow J.H., Abt H.P. el al, Efficacy of Arnica montana D4 for healing of wounds after hallux valgus surgery compared to diclofenac, $J$. Alternativ Complement Med.2008; 14(1): 17-25. 